\title{
El lujo cambiante. \\ El vestido y la difusión de las modas en la Corona de Aragón (siglos XIII-XV)
}

\author{
Juan Vicente García MarsiLla \\ Universitat de València \\ juan.v.garcia-marsilla@uv.es
}

\begin{abstract}
Resumen
La apariencia física de las personas era ya en la Baja Edad Media el primer indicativo de su condición social, pero en un período mucho más urbanizado e interconectado que los anteriores, el refinamiento de la indumentaria se convirtió en un hecho con unas connotaciones económicas, políticas y culturales de gran calado. El mismo incremento de la movilidad social llevó además a que no bastara con invertir grandes sumas en la propia imagen, sino que fuera necesario estar atento a los cambios de eso que llamamos "moda", cuyos orígenes se suelen situar en estos momentos en los que las clases dominantes tradicionales buscaban nuevos elementos de diferenciación frente a los advenedizos. Todo ello se analiza aquí a partir del ejemplo de la Corona de Aragón en los siglos XIII al XV.
\end{abstract}

Palabras clave: Moda, Vestido, Corona de Aragón, Movilidad Social, Distinción.

\section{Changing Luxury. Dress and Diffusion of Fashion Trends in the Crown of Aragon (13 ${ }^{\text {th }}-15^{\text {th }}$ Centuries)}

\begin{abstract}
The physical appearance of people was already in the late Middle Ages the first indication of social status, but in a period more urbanized and linked that the ones who came before, refinement of clothing became a fact with economic, political and cultural connotations of great significance. The same increase in social mobility also led to the fact that it was not enough to invest large sums in the image, but that it were necessary to be attentive to changes in what we call "fashion". The origins of this phenomenon can be placed in these times when traditional ruling classes were looking for new elements of differentiation against the upstarts. All these subjects are analyzed here using the example of the Crown of Aragon between the $13^{\text {th }}$ and $15^{\text {th }}$ centuries.
\end{abstract}

Key words: Fashion, Dressing, Crown of Aragon, Social Mobility, Distinction. 
Desde siempre la imagen que un individuo ofrece a sus semejantes ha sido muy importante para determinar quién es en la sociedad, y es evidente que la primera impresión que produce una persona la causa su misma apariencia, su ropa, su peinado, su aspecto, su olor. Pero cuanto más refinada sea esa sociedad más complejo será conseguir un aspecto adecuado a sus normas, que ponga la primera piedra de una buena reputación. La Baja Edad Media, un mundo más urbanizado y más interconectado que los períodos históricos inmediatamente anteriores, que tenía a su alcance una cantidad de productos, noticias e ideas infinitamente superior, y que además se caracterizó por una estructura social mucho más dinámica, fue uno de esos períodos de refinamiento, hasta el punto de que muchos estudiosos, no solo historiadores, sino también sociólogos o antropólogos, han hecho comenzar en ella ese fenómeno que llamamos "moda".

De hecho, muchas de las piezas de altísima calidad que una artesanía cada vez más especializada iba produciendo estaban pensadas para exhibirse aplicadas sobre el cuerpo, y la misma idea del lujo, que recibió un importantísimo empuje en este período, tenía en la elegancia en el vestir su máxima expresión. No es este, sin embargo, un tema nuevo. Las grandes escuelas de pensamiento llevan dedicándole ya muchas décadas de esfuerzo a razonar sobre él, e incluso en España el tema de la indumentaria en los siglos finales de la Edad Media ha sido objeto de muy remarcables estudios, partiendo de las obras pioneras de Carmen Bernis, y siguiendo por muchos estudios locales, como los de Isidra Maranges y Montse Aymerich para Cataluña, Cristina Sigüenza para Aragón, Pura Benito y Marisa Astor para Valencia o María Martínez y María del Cristo Marrero para la Corona de Castilla ${ }^{2}$. Gracias a ellos, o más bien a ellas, tenemos una parte del camino allanado, ya que se han dedicado sobre todo a la ímproba tarea de identificar piezas, de casar nombres de prendas con representaciones pictóricas y escultóricas de las mismas, y gracias a eso podemos saber de qué estamos hablando, qué nos dicen los documentos, e incluso algunos de

1 Véase por ejemplo R. KOENIG, La moda en el proceso de civilización, Valencia, 2002 [ed. original, Londres, 1991]; J. ENTWISTLE, El cuerpo y la moda: una visión sociológica, Barcelona, 2002 [ed. original, Londres, 2000]; y G. LIPOVETSKY y E. ROUX, El lujo eterno. De la era de lo sagrado al tiempo de las marcas, Barcelona, 2004 [ed. original, París, 2003]. Entre los estudios dedicados a la moda desde la Historia Medieval, cabe destacar S. TRAMONTANA, Vestirsi e travestirsi in Sicilia: abbigliamento, feste e spettacoli nel Medioevo, Palermo, 1993; F. PIPONNIER y P. MANE, Se vêtir au Moyen Âge, París, 1995; M.G. MUZZARELLI, Guardaroba medievale: Vesti e società dal XIII al XVI secolo, Bolonia, 1999; y M. SCOTT, Medieval dress \& fashion, Londres, 2007. Desde la arqueología y la cultura material son interesantes las páginas que dedica al vestido y las modas R. GILCHRIST, Medieval Life. Archaeology and the life course, Londres, 2013.

2 C. BERNIS, Indumentaria medieval española, Madrid, 1956, y Trajes y modas en la España de los Reyes Católicos, Madrid, 1978-1979; I. MARANGES, La indumentària civil catalana: segles XIII-XV, Barcelona, 1991; M. AYMERICH, L'art de la indumentària a la Catalunya del segle XIV, tesis doctoral leída en el Departament d'Història de l'Art de la Universitat de Barcelona, 2011; C. SIGÜENZA, La moda en el vestir en la pintura gótica aragonesa, Zaragoza, 2000; P. BENITO, La moda en la Valencia del siglo XV, Valencia, 2003; M. ASTOR, Indumentaria e imagen. Valencia en los siglos XIV y XV, Valencia, 1999; M. MARTÍNEZ, La industria del vestido en Murcia (ss. XIII-XV), Murcia, 1988, e "Indumentaria y sociedad medievales (ss. XIII-XV)", En la España Medieval 26 (2003), pp. 35-59, y "La creación de una moda propia en la España de los Reyes Católicos", Aragón en la Edad Media, 19 (2006), pp. 343-380; y M.C. MARRERO, La casa de Isabel la Católica. Espacios domésticos y vida cotidiana, Ávila, 2005. 
sus estudios nos han permitido trazar una mínima cronología de la aparición y desaparición de cada elemento de la indumentaria, un esquema básico de la evolución de las modas del pasado.

Sin embargo, queda aún mucho por hacer para entender un aspecto de nuestro pasado tan rico y sugerente como es el de la indumentaria, y los documentos, especialmente en el caso de la Corona de Aragón, a la que se dedican estas líneas, no faltan precisamente: en sus archivos se disponen miles de inventarios de bienes, de almonedas de los mismos, de pleitos ante la justicia, de contratos de confección, de libros de cuentas de reyes, nobles, mercaderes u hospitales, de crónicas y dietarios, de literatura moralizante, de leyes municipales y reales, y por supuesto en los museos, templos y bibliotecas abundan los retablos, las efigies funerarias, las pinturas murales, las miniaturas e incluso alguna, aunque escasa, pieza real que afortunadamente se ha conservado. Con todo eso, con ese material en bruto, las preguntas que se puede formular un historiador son muchísimas, por ejemplo ¿de cuántas prendas disponía una guardarropa medio? ¿Qué parte del presupuesto doméstico se invertía en ellas? ¿Dónde se compraban? ¿Con cuánta frecuencia? ¿Por qué vestían de esa manera? ¿Quién era el árbitro del "buen gusto"? ¿Gastaban de verdad más las mujeres que los hombres en su apariencia? Y si era así ¿por qué lo hacían?

Todas estas preguntas no son en absoluto baladíes, ni la indumentaria es un tema intrascendente, como los historiadores más tradicionales pretenden. Es necesario desechar ya la idea de que los temas relacionados con la vida cotidiana son inferiores a lo que siempre se ha considerado como la "gran historia", la política, los grandes planteamientos económicos o sociales, o la historia de los acontecimientos. En realidad nada de ello se puede entender sin comprender la base, la historia del consumo, de la lucha por la subsistencia, y también de los gustos estéticos, de las decisiones cotidianas que tomaban nuestros antepasados, que constituyen en realidad el verdadero esqueleto de la historia. Edificar las grandes teorías históricas sin aproximarnos a la mentalidad de la gente común en su día a día es como tratar de construir la casa por el tejado, y hace caer con mucha frecuencia en graves anacronismos.

Es en esa base del edificio histórico, en esa aproximación a lo cotidiano, donde se enmarcan las líneas que siguen, que consisten en una aproximación al mundo del vestido y la moda en un ámbito geográfico y cronológico concreto, y como se ha subrayado, especialmente rico en material de estudio, como es la Corona de Aragón entre los siglos XIII y XV. En el contexto de un volumen dedicado a las artes aplicadas y al discurso del lujo, el vestido constituye aquí un campo especialmente atractivo en el que se expresaron todas las formas posibles de distinción social, en el sentido en el que la definió el sociólogo Pierre Bourdieu, como marcador de las diferencias sociales en el marco de sociedades complejas ${ }^{3}$. Y para tratar de desgranar los distintos aspectos en que la indumentaria ejerció esa función vamos a estructurar el discurso en tres partes: una primera en la que se destaca la importancia de la indumentaria desde el punto de vista social y económico, y se tratan los importantes dispendios que se realizaban en la ropa; una segunda en la que, más allá del nivel de gastos, se intro-

3 P. BOURDIEU, La distinción: criterio y bases sociales del gusto, Madrid, 1991 [ed. original, París, $1979]$. 
duce un factor nuevo, como es el tiempo, y el carácter intrínsecamente cambiante de la moda; y una última en la que se analizan los mecanismos que los privilegiados trataron de desarrollar para frenar esa dinámica de la mutación que podía llevar a la ruina a los fashion victims de la época.

\section{Vestir y vestir bien. La importancia social y económica de la indumentaria}

Vestirse y proteger el cuerpo del frío y del entorno es para el ser humano una necesidad básica, solo menos básica quizá que la de alimentarse. Excepto en los climas ecuatoriales, todos debemos ponernos algo encima si queremos subsistir, y esta necesidad fue la que desarrolló la que seguramente fue la más importante de las industrias en la Edad Media: la textil. Aunque solo fuera por eso, porque las ciudades que cambiaron el rumbo de la historia partieron muchas de ellas de su dedicación a la confección de ropa, o de tejidos con los que fabricarla, es necesario entender qué vestían los hombres y mujeres de hace seis o siete siglos ${ }^{4}$.

La mayoría de ellos disponían de poco margen en sus modestos presupuestos domésticos como para invertir grandes cantidades en ropa. Podemos fijar un umbral económico mínimo para la indumentaria en casos como el de los catorce pobres que vistió el limosnero del duque de Gandía, Alfonso el Joven, en 1417. A cada uno de ellos le entregó una especie de cota exterior hecha de un paño azul de producción local, el "drap blau de la terra", y 3 alnas de lienzo o tela de lino para la ropa interior (2,718 metros), además de unos zapatos. En total el gasto por cabeza ascendió a unos 35 sueldos, a los que habría que añadir quizá otros 2 o 3 por las costuras del sastre 5 . De alguna forma estos eran unos pobres privilegiados, pero podemos suponer que con esa ropa pasarían todo el año, como tantos otros cuyo cadáver era reconocido por los testigos de los procesos judiciales por su ropa, ya que era la única que le habían visto siempre.

En cuanto a las mujeres tenemos también algún caso ilustrativo, como el de Pasquala, viuda de un labrador de Quart de Poblet, cerca de Valencia, llamado Andreu Martí, que en 1436, y después de pagar las numerosas deudas que dejó su marido, se quedó apenas con un brial o túnica interior, una huca o sobrevesta, un mantón, dos lligars o aderezos para la cabeza, un cosset o camisa interior y tres paños también para la cabeza, que era lo mínimo que consideraba necesario para "no exir e romandre despulada", es decir "para no salir y quedarme desnuda" 6 . Otros casos, especialmente pleitos ante la justicia, nos demuestran las pocas prendas que tenían las clases más humildes, como ocurre con el proceso, explicado por María del Carmen García Herrero, contra Lorenza Borraz, alias "la Morellana", que en 1462 mató en Zaragoza

4 Entre las muchas publicaciones sobre la importancia de la industria textil en la Edad Media, se pueden indicar algunas de las más antiguas actas de las Settimane del Datini de Prato, como la de 1970: M. SPALlANZANI (ed.), Produzione, commercio e consumo dei panni di lana nei secoli XII-XVIII, Florencia, 1976.

5 Arxiu del Regne de València (en adelante ARV), Mestre Racional 9.577, cuentas de gastos de Alfons el Jove, duque de Gandia, f. 148 r., 1417. El alna valenciana equivale a 0,906 metros.

6 ARV, Protocols de Jaume Ferrando 2.950, 7 de agosto de 1436. 
a una vecina suya, Antona Sanz, y se puso sus ropas, en concreto una camisa, unas "faldetas verdes" y una "gonella nueva de mescla forrada de blanqueta", un pañuelo de cuello y unas "calzas de mujer". Los vecinos las reconocieron inmediatamente, entre otras cosas porque la gonela le venía grande y la llevaba arrastrando, y le preguntaron que qué había hecho con su dueña. Ella contestó que Antona le había dado esas prendas, y uno de los testigos, llamado Pedro, le preguntó que, si era así, qué era lo que Antona llevaba puesto, porque no le conocía otras. Le contestó que la "saya bermella", pero Pedro le dijo que con eso no bastaba, por lo que la denunció y la morellana acabó ajusticiada por asesina ${ }^{7}$.

Tanto para hombres como para mujeres podemos por tanto cifrar en unos 40 sueldos valencianos anuales el precio de la indumentaria anual de una persona de las clases más bajas, lo que supone el salario de algo más de dos semanas de un oficial artesano $^{8}$. Superar ese umbral mínimo era ya comenzar a destacar, y desde luego un guardarropa bien surtido y constantemente renovado era uno de los signos externos más evidentes del éxito social. Las clases medias solían disponer de diez u once prendas de media por persona, que componían dos o tres conjuntos completos, pero las diferencias en sus precios eran realmente importantes, desde menos de cien sueldos por uno de estos ajuares a los 1.300 en que fue valorada la ropa de la mujer del jurista valenciano Agustí Genovés en $1380^{9}$. Poco más tarde, en 1395, otra mujer perteneciente a una cierta oligarquía ciudadana, la viuda del ciutadà de Valencia, Bartomeu Miró, estimaba en mil sueldos anuales sus gastos personales en vestir, pero otro miembro de la misma clase, Miquel de Penyarroja, cifraba en cambio en 1448 en 28 las complejas vestimentas de telas extranjeras de que disponía, entre ellas cinco caras gonelas de ricas telas como el terciopelo o el damasquino, dos cotas de paño florentino, una de ellas con forro de terciopelo y otra de piel de marta, otras dos cotas de paño inglés, otra más de Bruselas y diez camisas. Y el precio de este ajuar masculino se valoró ni más ni menos que en 3.034 sueldos $^{10}$.

Por supuesto, los guardarropas de los nobles eran mucho más caros, y los más encumbrados disponían incluso de sastres propios, a menudo extranjeros, que trabajaban en exclusiva para ellos y les diseñaban prendas a la última moda. Un buen ejemplo es de nuevo la familia de los Duques Reales de Gandía, que a finales del s. XIV disponía de dos sastres germanos, Hanequí y Petrequí de Alamanya, y otro seguramente francés, Rotlan de Nay, de los que tenemos cuentas de los jubones, hopalandas, "mantones botonados" y otras prendas que iban cosiendo. En 1370, por ejemplo, Petrequí d'Alamanya recibió el encargo de vestir con gonelas de paño rojo a las doncellas de doña Violant d'Arenós, la esposa del duque, y llenó cada una de ellas con 5 docenas de botones y numerosas anillas, mientras que a la duquesa le hacía otra igual pero con 10 docenas de botones, muestra de hasta que punto los botones, a

7 M.C. GARCÍA HERRERO, "Una burla y un prodigio. El proceso contra la morellana (Zaragoza, 1462)", Aragón en la Edad Media, 13 (1997), pp. 167-194.

8 En el s. XV el jornal de un oficial artesano solía variar entre los 3 sueldos y 3 sueldos y medio.

9 ARV, Justicia Civil, Vendes Menors 425, 2 de abril de 1380.

10 Respectivamente en ARV, Justícia Civil, Requisicions 692, mano 3, fol. 27, 14 de julio, y Arxiu de Protocols del Patriarca de València (en adelante APPV), Protocols de Ambrosi Alegret 20.716, 5 de abril. 
menudo de metales preciosos, eran un símbolo de poder entonces, y de cómo la indumentaria servía para marcar la jerarquía en la corte ${ }^{11}$. Los encargos que estos sastres extranjeros recibían están apuntados a veces con sumo detalle, y expresan el refinamiento de los vestidos de la nobleza. Hanequí, por ejemplo, estando en el Castillo de Garci Muñoz, una de las propiedades de su señor como marqués de Villena que era en esos momentos, en 1378, hizo para el hijo menor de su señor una "jaqueta forrada vermella de çaytoni", es decir, una chaqueta roja de satén para la que compró 12 alnas de lienzo, 2 libras de algodón para el relleno, e hilo de seda para coserla, cobrando 62 maravedís por su trabajo. Y después le realizó también un caperó (capuchón), una hopa y un mantell botonado, mientras que Petrequí hizo para el marqués dos jubones de paño de Courtrai forrados de lienzo y con bordados de seda, una gramalla con caperó, una hopalanda roja y una zamarra, costando solo su trabajo 45 sueldos y 6 dineros ${ }^{12}$.

No extraña por tanto que las ropas de los grandes personajes se convirtieran en un espectáculo público comentado por toda la sociedad y en el que se fijaban a menudo los cronistas. A veces, leer en alguno de los dietarios bajomedievales los episodios de la aparición pública de algún rey o reina nos recuerda con fuerza a las narraciones que aparecen hoy en día en las revistas del corazón, o en programas televisivos "de sociedad", donde se nos describe, por ejemplo, cómo iban vestidos los famosos para la gala de los Oscars. Tomemos como ejemplo el dietario o Llibre de Jornades del barcelonés Jaume Safont, que abarca casi todo el s. XV. En él nos describe que cuando Juan II entró en Barcelona para jurar sus Usatges en 1458 iba vestido "con una ropa de lana oscura floreada de martas cibelinas, larga hasta las puntas de los pies, con un gorro de piel negra en la cabeza". Su desgraciado hijo Carlos de Viana, dos años más tarde, entró en la ciudad "a caballo, vestido con una ropa de damasquino marrón y un bonete morado en la cabeza y un capuchón de paño oscuro, y llevaba un muy rico collar de oro con muchas perlas gruesas y de gran valor". Y también Fernando el Católico visitó la Ciudad Condal con solo nueve años, acompañado de su madre, y Safont retuvo igual de minuciosamente en su retina la apariencia de ambos: Juana Enríquez vestía "una clocha larga de terciopelo azul con gonela de terciopelo carmesí" y el niño "una ropa de terciopelo negro, con un collar de oro, diamantes y piedras finas" ${ }^{\prime 3}$. Vemos, de hecho, que los colores oscuros sobre tejidos jaspeados

11 ARV, Mestre Racional 11.593, Llibre d'Albarans del Duc de Gandia, papel suelto en el forro titulado "Averies d'infants e doncelles". En la década de 1370 Petrequí y Rotlan de Nay recibían el apelativo de "sastre de casa mia", mientras que a Hanequí se le llamaba "sastre de casa de don Pedro", el hijo menor del entonces marqués de Villena, luego duque de Gandía. Se les pagaban a todos ellos pensiones y gracias, además de extras por la confección de ropas. Estando en Castilla recibían 2 maravedís diarios, el equivalente a 4 dineros valencianos, para su comida. Sobre el valor de los botones en esta época véase Ch. FRUGONI, Botones, bancos, brújulas y otros inventos de la Edad Media, Barcelona, 2008 [ed. original, Roma, 2004].

12 Ibid.

13 Dietari o Llibre de jornades (1411-1484) de Jaume Safont, edició a cura de Josep Maria Sans i Travé, Barcelona, 1992, en la p. 106 se describe a Juan II, "E vench vestit d'una roba de drap de llana scura florada de gibillins, larga fins a les puntes dels peus, ab un capell de pèl negra al cap"; en la p. 120 se habla de la apariencia de Carlos de Viana, "vench a cavall, vestit d'una roba de domesquí burell ab un bonet morat al cap e ab caperó de drap scur, e portà un molt ric collar d'or ab moltes perles groces e de gran valor"; y en la p. 143 , de la de Fernando el Católico y su madre "E aprés venia lo dits enyor primogènit, vestit d'una roba de 
comenzaban a predominar para que se apreciarse mejor sobre ellos el brillo de todas estas joyas.

La apariencia regia no era, por tanto, un tema menor en la política de la época, ya que certificaba el poder y sobre todo la solvencia económica del monarca ante sus rivales y sus acreedores. De ahí por ejemplo la preocupación que mostró Alfonso el Magnánimo días antes de entrar triunfalmente en Nápoles, en 1443, por recuperar sus joyas, y especialmente un broche o fermall de piedras preciosas que tenía empeñado a dos nobles valencianos, Joan de Pròxita y Galceran de Requesens, por nada menos que 220.000 sueldos. De hecho, llegó a vender a la ciudad de Valencia el señorío de la villa de Cocentaina para rescatarlo rápidamente y así poder lucirlo durante la ceremonia ${ }^{14}$.

Los gastos de la tesorería de este rey muestran en efecto la importancia que le concedía a su guardarropa, y eso que, según uno de sus cronistas y aduladores, Antonio Beccadelli "il Panormita", "usaba moderadamente de vestidos y arreos... y decía a menudo que deseaba mostrarse rey por virtud y autoridad y no por púrpuras ni corona" ${ }^{15}$. Pero como siempre, la virtud de la sobriedad es siempre relativa, y si analizamos sus cuentas vemos que el Magnánimo gastaba en el cuidado de su apariencia física alrededor de doscientos mil sueldos al año, es decir, entre el 10 y el $15 \%$ del presupuesto de la tesorería, el equivalente a los ingresos de un año en la Bailía de Valencia, o al precio de doscientos caballos de guerra o de trescientas casas en la ciudad de Valencia ${ }^{16}$. De hecho, las mismas telas que adquiría sobre todo de mercaderes italianos afincados en Barcelona o Valencia, en especial sedas damasquinadas o terciopelos, alcanzaban precios astronómicos. Así el satén carmesí, sin ser de los más caros, costaba por ejemplo a 99 sueldos el alna, mientras que el satén aterciopelado negro se pagaba a más de 300. Frente a ello, el drap de la terra, el de lana de uso común que se compraba a veces para los criados, valía solo 9 sueldos y medio el alna ${ }^{17}$.

\section{El dinero no lo es todo. El "factor moda" en sus orígenes}

Sin embargo, pese a estas enormes diferencias de precio, si algo caracteriza a este período es precisamente que ya no bastaba con tener dinero para estar bien considerado desde el punto de vista de la apariencia, sino que comenzaron a introducirse factores nuevos para convertir la vestimenta en una forma de distinción social. En efecto, tendemos a considerar la etapa medieval como lastrada por un verdadero inmovilis-

\footnotetext{
vallut negra, ab un collar d'or ab molts diemants e altres pedres fines, e tan tost al detraç venia la senyora reina, vestida ab una clotxa larga de vallut blau ab gonella de vallut carmesi".

14 Arxiu de la Corona d'Aragó (en adelante ACA), Reial Cancelleria, Curiae 2.653, ff. 11v-12v, 28 de septiemrbe de 1443. Citado en J.V. GARCÍA MARSILLA, "Intercanvis culturals i lideratge estètic. La demanda artística d'Alfons el Magnànim en el context de l'Europa del quatre-cents", en M.R. TERÉS (ed.), Capitula facta et firmata. Inquietuds artístiques en el quatre-cents, Valls, 2009, p. 131.

15 A. BECCADELLI, Dels fets e dits del gran rey Alfonso, E. DURÁN (ed.), Barcelona, 1998, p. 98.

16 Véase el capítulo "Vestir el poder" en J.V. GARCÍA MARSILLA, Art i societat a la València medieval, Catarroja-Barcelona, 2011, pp. 291-311.

17 Ibid., pp. 300-301.
} 
mo social, lo que no es ni mucho menos cierto. A partir del auge de las ciudades que se inicia en el s. XI nuevas clases sociales, y especialmente la naciente burguesía, comenzará a acumular riquezas que en algunos casos hacían palidecer las fortunas de los nobles. Las investigaciones de las últimas décadas demuestran además que el campesinado no era ya en estos momentos un bloque social monolítico, sino que se agrandaban las diferencias en su seno y algunos labradores llegaron a acumular tierras, ganado y poder local, hasta convertirse en "notables de aldea", y llegar a niveles económicos que a veces superaban fácilmente a los de la pequeña nobleza ${ }^{18}$. Por tanto, aunque seguían existiendo los estamentos, y los privilegios de nobles y clérigos, muchas veces esas prerrogativas no iban acompañadas de un predominio económico paralelo. Incluso, aunque pasar de un estamento a otro era realmente difícil, no son raros los ejemplos en los que a lo largo de dos o tres generaciones se accedía a la nobleza gracias a servicios o préstamos a los monarcas, o escalando a través de los cargos eclesiásticos. La trayectoria de los valencianos Borja, desde una oscura baja nobleza local a dar dos papas a la Cristiandad, es en ese sentido emblemática ${ }^{19}$.

Por todo ello no es casualidad que se popularizase en la iconografía de la época la famosa "Rueda de la Fortuna", y por eso, para las clases privilegiadas, y especialmente para la nobleza, e incluso para las añejas oligarquías patricias de algunas ciudades que veían como nuevos ricos comenzaban a hacerles la competencia, el dinero dejó de ser, por fuerza, el único factor de diferenciación. Tuvieron que buscar otras estrategias que les permitieran seguir considerándose superiores y separarse de los advenedizos. En ese sentido, el factor tiempo, expresado en lo que llamamos "moda", fue sin duda un gran hallazgo, ya que al hacer que los conceptos estéticos, que el gusto, cambiara constantemente y en plazos relativamente cortos, se obligaba a un empleo de tiempo, recursos y contactos que casaba mejor con las elites tradicionales que con los siempre atareados burgueses. En efecto, ya no bastaba con ser muy rico e invertir grandes sumas en las mejores telas y en joyas para adornarlas, sino que ahora además era necesario invertir mucho tiempo en ponerse al día de lo que era "el último grito", y además tener acceso a los que imponían las nuevas tendencias, normalmente las cortes reales. Todo eso lo proporcionó la moda ${ }^{20}$.

Pero ¿cuándo comenzó a evolucionar la moda? Los principales estudiosos del fenómeno marcan un punto de inflexión hacia mediados del s. XIV, pero en realidad, ya en el XIII se encuentran novedades interesantes y mutaciones que tratan de hacer

18 Significativo de esta percepción mucho más matizada de estas clases sociales, y de esa insuficiencia de los términos "noble" o "campesino" a la hora de caracterizar la realidad social de las personas a finales de la Edad Media es el título escogido por un grupo de jóvenes medievalistas de diversas nacionalidades para el libro coral, F. APARISI y V. ROYO (eds.), Beyond Lords and Peasants. Rural Elites and Economic Differntiation in Pre-Modern Europe, Valencia, 2014.

19 Entre las muchas publicaciones dedicadas a esta familia desde hace unos años destacaremos Xàtiva, els Borja, una projecció europea, Xàtiva, 1995.

20 Sobre el fenómeno de la moda desde un punto de vista cultural y antropológico véase por ejemplo D. ROCHE, La Culture des apparences. Une histoire du vêtement (XVIIe-XVIIIe siècles), París, 1989; Ch. BREWARD, Cultures, Identities, Histories: Fashioning a Cultural Approach to Dress, Nueva York, 1998; y K. TRANGBERG HANSEN, "The World in Dress: Anthropological Perspectives on Clothing, Fashion and Culture", Annual Review of Anthropology, 33 (2004), pp. 369-392. 
visible una cierta segregación social ${ }^{21}$. En esos momentos los marcadores de estatus tenían que ver aún con aspectos bastante evidentes de poder económico y social, dado que estamos todavía al principio del proceso. Así, se estilaban los trajes largos, tanto para hombres como para mujeres, básicamente porque incluían más metros de caras telas. Los colores eran difíciles de conseguir, y especialmente los más llamativos, que además se cargaron de significados simbólicos por influencia tanto del cristianismo como de las novelas de la "materia de Bretaña". Al principio el rojo y el verde eran los más preciados, después la popularización del tinte azul con hierba pastel producida en Lombardía y Occitania, y la asunción de este color en la heráldica de los reyes de Francia, hizo la fortuna de los trajes de este color. Igualmente las prendas de dos colores, o "meitadats" en la documentación en catalán, pasó de ser propia de los criados a convertirse en algo elegante al final de la centuria, cuando las técnicas de la sastrería y del tintado mejoraron lo suficiente como para obtener resultados brillantes.

Pero algunas de las nuevas modas que se comenzaron a imponer eran más sutiles en cuanto a los mensajes sociales que lanzaban. Por ejemplo en el s. XIII hispánico se hace frecuente abrochar los vestidos con complejas cordadas laterales, los "margomados", imposibles de ajustar sin la ayuda de otra persona. De hecho, esto era precisamente lo que se buscaba: demostrar que se disponía de criados o esclavos que participaban en el complejo ritual de vestir al señor, como más tarde ocurrirá con los corsés y miriñaques del s. XIX. De hecho, durante mucho tiempo lo cómodo fue enemigo de lo elegante precisamente porque lo que se trataba de transmitir era que aquellas personas que portaban trajes a la moda no necesitaban de su cuerpo para nada útil, sino como simple percha para las últimas tendencias.

Por un proceso parecido, en el s. XIII se pusieron de moda ropas que dejaban a la vista las prendas que se llevaban debajo, para así poder lucir también esa acumulación de tela. Como ejemplo tenemos el muy hispánico "pellote", en sus dos versiones, masculino y femenino, que permitía apreciar perfectamente las superposiciones, tal y como se puede apreciar tanto en las miniaturas de las Cantigas como en los restos auténticos de dichos vestidos hallados en las tumbas de las Huelgas ${ }^{22}$. No es muy difícil aquí actualizar el tema y pensar en la moda presente de los pantalones caídos, que aunque surgida en las cárceles americanas, triunfa sobre todo porque permite enseñar lo mucho que el que los exhibe se ha gastado en unos calzoncillos Calvin Klein.

En el s. XIV esa tendencia a permitir la visión de las capas interiores del vestido fue manifiesta por ejemplo en el ensanchamiento de las mangas, a través de modas francesas como la "cotardía", de cotte hardie, "cota atrevida", que en la Corona de Aragón, como demostrara Montse Aymerich, es una novedad que trae la monarquía hacia la década de 1330, mientras que se difunde entre la población una década más tarde, según lo prueban los inventarios de algunos mercaderes barceloneses ${ }^{23}$. Pero

21 Las siguientes ideas aparecen expresadas en J.V. GARCÍA MARSILLA, "Vestit i aparença en els regnes hispànics del segle XIII", R. NARBONA (ed.), Jaume I i el seu temps 800 anys després, Valencia, 2012, pp. 621-646.

22 Véase respectivamente G. MÉNENDEZ PIDAL, La España del siglo XIII leída en imágenes, Madrid, 1986, y J. YARZA et al., Vestiduras ricas: el Monasterio de las Huelgas y su época (1170-1340), Madrid, 2005.

23 M. AYMERICH, op. cit., 201, pp. 179 y ss. 
la cotardía suponía también, además de una forma de mostrar la ropa de dentro, y también a veces los forros de pieles de la prenda, un auténtico incordio para moverse o, como explicaba Eiximenis, para comer, ya que era frecuente meter la manga en las salsas $^{24}$. La estética se estaba pues imponiendo a la practicidad, lo mismo que vemos en los zapatos, cuyas puntas se alargan y retuercen, y generan dolores y callos como denuncian también los moralistas. Algo que pueden entender muy bien actualmente las mujeres que se atreven a calzar tacones de aguja ${ }^{25}$.

Comienza sin embargo, como hemos dicho, en estos años centrales del Trescientos, el gran cambio en las hechuras de las ropas, especialmente de las masculinas. De alguna manera se trató a partir de entonces de mostrar más el cuerpo, pero de una forma un tanto mentirosa, ya que ese cuerpo que se exhibía estaba adaptado a un ideal de belleza que se conseguía a menudo con rellenos y postizos. Es el gran momento de los jubones, piezas cortas y entalladas de difícil confección que incluían con frecuencia hombreras y abombados, para dar la imagen de unas anchas espaldas que muchos en realidad no poseían. El jubón dio lugar incluso a oficios especializados en él, los juponers o giponers en la Corona de Aragón, cada vez más abundantes en las ciudades, y que con frecuencia se encuadraban en la misma cofradía que los calceters, es decir, los especialistas en las calzas o medias que completaban el nuevo "vestido corto" de los hombres ajustándose a las piernas y mostrando por tanto la anatomía de la parte baja del cuerpo ${ }^{26}$. Algo que los moralistas consideraron durante mucho tiempo una desvergüenza, pues el mismo Eiximenis denunciaba a aquellos que le servían a la mesa casi con la cara tapada pero mostrándole llurs vergonyes ${ }^{27}$.

La explicación habitual de este profundo cambio suele ser que las novedades en la indumentaria militar, con la generalización de las armaduras de "punta en blanco", es decir, de placas de metal, frente a las antiguas cotas de malla, trajo como consecuencia mostrar de forma más patente la anatomía y tener que ajustar sobre ella las prendas de adorno en las que se disponían sobre todo los blasones heráldicos ${ }^{28}$. Sin embargo pensemos que el cambio es mucho más profundo. En realidad, los antiguos

\footnotetext{
24 F. EIXIMENIS, Lo Crestià, Terç del Crestià, cap. DCCXIV, Qui reprén en les vestedures e calçaments tall va e vana forma, edición de A. HAUF, Barcelona, 1983, pp. 158-161,

25 “...E encara fa lo diable que porten lo peu així polit, estret, que sovint l'estretura los procura poagre, e els dóna sovint tals pena que qui els dava semblant pena en penitència, que no la portarien per res..." (y aún hace el diablo que lleven el pie tan pulido y estrecho que a menudo la estrechez les causa gota, y les da a menudo tanta pena que si se la hubieran mandado como penitencia no la soportarían por nada), ibid., p. 159.

26 En Valencia los juboneros trataron de separarse del gremio de sastres al menos desde 1418, en que, junto con los vanovers o fabricantes de mantas, ya crearon una cofradía propia (J. CASTILLO y L.P. MARTÍNEZ, Els gremis medievals en les fonts oficials. El fons de la Governació del regne de València en temps d'Alfons el Magnànim (1417-1458), Valencia, 1999, pp. 105-107. Véase también los datos que aporta sobre este oficio la monografía sobre el gremio de sastres de R. DE PUERTA, Historia del Gremio de Sastres y Modistas de Valencia, Valencia, 1997.

27 “...aixi que si us serveixen quan menjarets, per força vos han de fer cimbell de llurs vergonyes, qui, segons bona raó, vos deurien provocar a vòmit..." (así que si os sirvieran cuando comieras os han de hacer ostentación de sus vergüenzas, que, según buena razón, os deberían provocar vómito), F. EIXIMENIS, op. cit., 1983, p. 158.

28 Entre otras muchas obras, esta explicación aparece contenida en la reciente y bien ilustrada obra de C. FRANKLIN et al., Moda. Historia y estilos, Londres, 2012, pp. 68-72. Sobre esta gran transformación F. PIPONNIER y P. MANE, op. cit., 1995.
} 
guerreros, fuertes y atléticos, estaban dejando paso a unos dandies mucho más refinados, más atentos a la literatura, la música y la danza, que al combate, pero que a través del vestido aspiraban a seguir mostrando los ideales bélicos de sus antepasados.

En el caso de las mujeres el cambio no fue nunca tan radical. El traje básicamente siguió siendo largo, aunque se agrandaron los escotes, y sobre todo se innovó mucho en los tocados, algunos bastante estrafalarios, como los cónicos que llegaban de Francia o los que, desde Flandes, se impusieron desde el s. XIV y que se llamaban popularmente "de cuernos". Refiriéndose a estos últimos San Vicente Ferrer llegó a afirmar en sus sermones que las mujeres que los llevaban ofendían a Dios, porque él las había hecho humanas y ellas preferían ser vacas o cabras ${ }^{29}$.

Evidentemente una pregunta que surge de inmediato es cuál era el ritmo de estas mutaciones. Es este un tema que en realidad está todavía por estudiar en profundidad, pero en líneas generales podemos ya afirmar, por una parte, que las grandes hechuras de las prendas tardaban bastante más en alterarse que hoy en día, y se trataría de cambios para los que habría que esperar décadas. Estamos hablando en este caso de mutaciones tan importantes como el nacimiento del vestido corto que hemos explicado, o la generalización de las clochas o vestidos abiertos por delante que se produce poco a poco a partir de la década de 1430 y hasta el s. XVI, o la difusión de nuevos colores, más oscuros, que se observa en esa misma cronología, con predominio del negro, el azul y el violeta ${ }^{30}$. Pero al mismo tiempo existían otros ciclos, muchos más cortos, que se concentraban más bien en detalles, a menudo arbitrarios, que servían para evaluar si una persona estaba o no a la moda. Esta evolución más rápida es la que hizo bramar a Eiximenis contra aquellos que "cada año mudan de forma de vestir", explicando cómo para distinguirse, un año se llevaban las calzas por fuera de los zapatos "contra todo sentido" según él, y al año siguiente otra vez por dentro, y cómo cambiaban las colas de los vestidos femeninos de año en año ${ }^{31}$. Antes incluso de que naciera Eiximenis, que como sabemos vivió a caballo entre los siglos XIV y XV, en unas ordenanzas de corte aprobadas en Castilla por Alfonso X el Sabio a mediados del s. XIII ya se obligaba a que las vestiduras debían durar a todo el mundo al menos un cierto tiempo, y que nadie pudiera hacerse más de dos capas vistosas, forradas con piel, al año, o una capa aguadera cada dos, señal de que los más potentados desechaban estas prendas incluso con mayor rapidez para comprar otras ${ }^{32}$.

\footnotetext{
29 “... quan pensa una dona: 'O Deu m'a feta dona, e jo me so feta cabra o vaca, ab aquells corns e plena de vent e pompa... après vosaltres, mes filles, que Deu vos ha fet dones e elles fan-se cabres o vaques ab aquells corns" (V. FERRER, Sermons, Barcelona, 1934, vol. I, Feria II Post Octavam Ascensionem, pp. 30 y 35). Véase también P. IRADIEL, "Tenir cura del cos, tenir cura de la imatge. Els paradigmes de la bellesa femenina al a València de la Baixa Edat Mitjana", Debats, 16 (junio, 1986), pp. 4-19, y M.P. BENITO, op. cit., 2003, pp. 59-68.

30 Sobre los colores M. PASTOUREAU y D. SIMONET, Breve historia de los colores, Barcelona, 2006 [ed. original, París, 2005].

31 “...en altres hòmens ha posada folia major, ço és, que vagen en peals de calces, e les sabates són dins les calces, contra tota costuma del món e contra raó..." F. EIXIMENIS, op. cit., 1983, p. 159.

32 J.D. GONZÁLEZ ARCE, Apariencia y poder. La legislación suntuaria castellana en los siglos XIII$X V$, Jaén, 1998, p. 102. En Francia se limitaba en 1279 a cinco los conjuntos de ropa que podía comprar en un año un miembro de la alta nobleza, a entre 2 y 4 los caballeros según su rango, y los burgueses solo a una (M. SCOTT, op. cit., 2007, p. 73).
} 
Esas modas nuevas venían a menudo de fuera, en un mundo, como hemos dicho, más interconectado gracias a los continuos viajes de los mercaderes y de las cortes. Se introducen de esta manera constantemente no solo tejidos de diferentes procedencias, primero los franceses y los flamencos, más tarde los italianos y por último, hacia 1430, los ingleses, sino que también se importan formas de vestir, prendas y en general, nuevas ideas sobre la apariencia. La corte debió ser en esto muy importante, porque buscaba continuamente las novedades fuera para sorprender, y a menudo contaba con sastres, peleteros, zapateros o barberos foráneos ${ }^{33}$. Esto ya se observa con Pedro el Ceremonioso, y aún más con sus hijos Juan I y Martín el Humano, casados con damas francesas, pero el cosmopolitismo llega al culmen con Alfonso el Magnánimo, cuya apariencia la diseñaban los sastres franceses Robí Lamassen y Ayne de Clève, los peleteros catalanes Joan Sapinya y Lluís Pelat, el zapatero de la Picardía Simon Picart y el francés Lambert lo Ligoys, el bordador italiano Conti del Castello, los plateros toscanos Guido Antonio y Giovanni da Pisa, y el barbero siciliano Angelo da Catania ${ }^{34}$.

No cabe duda de que todo esto acabaría por generar una cierta globalización del vestido, al menos en las grandes cortes. Sin embargo, diversos datos nos permiten suponer que la homogeneización de gustos en la vestimenta a escala europea no fue completa en estos siglos, al menos para el conjunto de la sociedad. Por eso los viajeros describen todavía con curiosidad los usos indumentarios de los lugares que visitan, descubriéndonos a veces cómo predominaban unas u otras procedencias foráneas en la moda de una localidad. Así en 1446 un mercader florentino establecido en Valencia escribía a su madre, Alessandra Macinghi degli Strozzi, y le decía: “Tendrías que ver cómo van vestidos por la calle, igual que los que aparecen pintados en lo tapices, pero no llevan los mismos tocados, sino que las mujeres, por muy viejas que sean, llevan una red en la cabeza y sobre ella un velo, que no lo llevan como vosotras las tocas, sino que lo llevan abierto, y parece que tengan alas en la cabeza, y no llevan los mantos de seda, sino que todos son de paño, con una cola larga que llevan en la mano la gente de su casa" ${ }^{35}$. Además de muchas modas locales, quizá lo que más llame la atención es la comparación con "los que están pintados en los tapices", que iguala a los valencianos con los flamencos, a pesar de los matices que va incluyendo más tarde. Sin embargo, tampoco un nórdico como Jerónimo Münzer a finales del s. XV se identificaba totalmente con la apariencia de los valencianos que veía por la calle, que describe de la siguiente manera: "Visten los hombres ropa larga y las mujeres con singular, pero excesiva, bizarría, pues van escotadas de tal modo que se

33 Véase J.V. GARCÍA MARSILLA, “Mestres d'ultramar”, ÍDEM, op. cit., 2011, pp. 273-290.

34 J.V. GARCÍA MARSILLA, "Vestir el poder", ibid., pp. 291-311.

35 "Avisovi che se voi vedessi come costor vanno vestit, a punto come quelli che stanno dipinti in su li panni d'arazzi; ma non hanno quello mazzochio; che vecchia che sia, porta una rete di seta in capo, e suvi uno velo iscempio: nollo portano il velo come voi lo sciagatoi; lo tengono disteso; pare che abbiano l'ale al capo ch'ène una gentile cosa. E no portano le cioppe di seta: tutte le cioppe sono di pann, con gozzi a trombe, e una coda lunga cinque braccia o più, e le gente di casa loro pigglino la coda e loro tengo in mano....". A. MACINGHI DEGLI STROZZI, Lettere di una gentildona fiorentina del secolo XV ai figliuoli esuli, Florencia, 1877, pp. 29-30, carta fechada el 28 de abril de 1446. Agradezco a Matilde Miquel el haber llamado mi atención sobre estas cartas. 
les pueden ver los pezones; además todas se pintan la cara y usan afeites y perfumes, cosa en verdad censurable" ${ }^{36}$. De hecho, incluso en el s. XVI se editaron auténticos catálogos de indumentaria por países, como el Trachtenbuch del alemán Cristoph Weiditz, que remarcaban las grandes diferencias de unas regiones a otras, mostrando dibujos de hombres y mujeres valencianos, vascos o granadinos, con indumentarias completamente distintas y algunas, quizá, bastante exageradas ${ }^{37}$.

¿Qué vías tenían en todo caso las novedades para difundirse por los diversos escalones de la sociedad? Aunque existen excepciones, debemos pensar en los reyes y sus cortes como grandes promotores de la novedad, y como los únicos que tenían el derecho, y casi la obligación, de innovar. Es el caso, varias veces citado, de Alfonso el Magnánimo, en cuyas cartas a sus proveedores habituales se observa una obsesión porque todas las piezas que compraran fueran, según sus instrucciones "de la más extraña y nueva manera que se pueda encontrar"38. A partir de ahí comenzaba a funcionar la pirámide descendente de la innovación y la moda, a través de varios mecanismos. Uno de ellos, quizá el más tradicional, y podríamos decir "feudal”, eran los regalos que se hacían a los vasallos y subordinados. El Magnánimo mismo solía repartir prendas, a veces usadas por él anteriormente, otras veces nuevas, entre su entorno, o hasta por la calle, como ocurrió en Valencia en el día de Reyes de 1426, cuando fue caminando desde su residencia en el Palacio del Real a la catedral para oír misa, repartiendo "muchas clochas de brocado a los caballeros de Valencia" ${ }^{39}$. Pero incluso en los testamentos de personas de clases sociales más modestas son bastante frecuentes los regalos en forma de prendas de vestir que se hacen a familiares, o incluso a sirvientes o esclavos ${ }^{40}$.

Pero tan importante o más que la lógica del don era ya en esta época la del mercado, y especialmente del mercado de segunda mano, en cuyo estudio me he centrado en los últimos años. Lo que ahora llamamos reciclaje o economía sostenible se practicaba ya entonces, aunque por razones bien distintas en general a las que lo justifican en la actualidad, al menos hasta que comenzara la crisis que nos azota. De hecho, como hemos visto, la mayoría de la población debía hacer durar mucho más las prendas que hoy en día, y no faltan casos de reciclado de ropas, como el que se observa en un proceso barcelonés de 1374 en el que Antonia, la esposa de un mercader, se acerca

36 J. MÜNZER, Viaje por España y Portugal, Madrid, 1924, p. 37 y ss.

37 C. WEIDITZ, El Libro de los Trajes, Valencia, 2001. Véase también el códice de trajes de la Biblioteca Nacional de España, llamado tradicionalmente "Códice Madrazo-Daza", sobre el que se ha publicado recientemente el artículo de T. MEZQUITA, "El Códice de Trajes de la Biblioteca Nacional de España", Goya, 346 (2014), pp. 16-41.

38 Frase que se repite con frecuencia en las cartas de este rey a sus proveedores. por ejemplo en 1456 , cuando encargó dos pentinadors y dos confiters, de paño de Cambrai recubiertos de oro "de la més stranya e nova manera que fer puxen" (ARV, Mestre Racional 9.826, f. 99v). El pentinador era una pieza de tela que se ponía sobre los hombros cuando se peinaba al rey, para que no cayeran pelos sobre su ropa, mientras que el confiter era una tela preciosa sobre la que se disponían los todavía muy caros pasteles o confites.

39 J.V. GARCÍA MARSILLA, "Vestir el poder", Idem, op. cit., 2011, p. 304.

40 Como ejemplo de esta irradiación hacia las clases más bajas de las ropas del difunto tenemos entre otros la entrega de una gramalla al médico Pere Pintor por parte del noble Lluís de Castellví (APPV, Protocols de Francesc Pintor 22.552, 19 de abril de 1481). 
por casa del sastre judío Bonín para que "le cortase una gonela de una cota amplia que le habían traído de Génova"41.

En realidad, casi todos los días en la plaza dels Encants de Barcelona, o en la del Mercado de Valencia, se llevaban a cabo numerosas almonedas de bienes de difuntos para conseguir liquidez con la que pagar las deudas y el sepelio, y allí se congregaba prácticamente toda la sociedad local para conseguir ropas a buen precio. En todo caso eran bastante más baratas que las nuevas, lo que permitía que sectores más modestos tuvieran acceso a las novedades, y que la moda, aunque con un cierto desfase cronológico, fuera calando en todo el cuerpo social. Tan importante fue este mercado que se hubo de regular de forma puntillosa, y surgieron oficios especializados en él, como los pellers o ropavejeros, algunos de los cuales llegaron a ser realmente ricos ${ }^{42}$.

\section{Frenar la "Rueda de la Fortuna". Ideología y leyes suntuarias}

Sin embargo, el rápido sucederse de las modas y los estilos parece que no fue suficiente para marcar por sí solo las diferencias sociales, y de forma artificial y desde arriba se llegó a regular lo que cada uno podía vestir en función de su rango y condición, en lo que ahora llamamos "leyes suntuarias". Son estas un fenómeno que, por lo que sabemos, comenzó en algunas ciudades italianas, como Génova, a finales del s. XII, y que llegó a la Península Ibérica poco después, a lo largo del s. XIII, para instalarse durante un largo período, prácticamente hasta las revoluciones burguesas del XIX ${ }^{43}$. Ya en 1788 el ilustrado alicantino Juan Sempere y Guarinos le dedicó a este tema una monografía a escala estatal, y sus estudios se han ido actualizando en los últimos años, más en la Corona de Castilla que en la de Aragón ${ }^{44}$.

41 J.A. RABELLA I RIBAS, Un matrimoni desavengut i un gat metzinat. Procés criminal barceloní del segle XIV, Barcelona, 1998

42 J.V. GARCÍA MARSILLA, "La vida de las cosas. El mercado de objetos de segunda mano en la Valencia medieval", ponencia al congreso Pautes de consum i nivells de vida al món rural medieval, Valencia, 2008 (accesible en línea: www.uv.es/consum), y "Avec les vêtements des autres. Le marché du textile d'occasion dans la Valence médiévale", L. FELLER y A. RODRÍGUEZ (dirs.), Objets sous contrainte. Circulation des richesses et valeur des choses au Moyen Âge, París, 2013, pp. 123-143, y "Empeñando la vida. Los préstamos con prenda mueble en la Valencia medieval", M. CARBONI y M.G. MUZZARELLI (eds.), In Pegno. Oggetti in transito tra valore d'uso e valore di scambio (secoli XIII-XX), Bolonia, 2012, pp. 133-168, y "Expertos de lo usado. Pellers, ferrovellers y corredors de coll en la Valencia medieval", ponencia al coloquio Expertise et valeur des choses au Moyen Âge (2). Compétences et figures d'experts, Valencia, octubre 2011; y J.V. GARCÍA MARSILLA, G. NAVARRO y C. VELA, "Pledges and auctions: The Second-Hand Market in Late Medieval Crown of Aragon", ponencia a la XVI Setimana Datini di Prato. Il commercio al minuto tra economia formale ed economia informale (secc. XIII-XVIII), Prato, abril de 2014.

43 Véase entre las obras más actuales sobre estos temas de M.G. MUZZARELLI y A. CAMPANINI (eds.), Disciplinare il lusso: la legislazione suntuaria in Italia e in Europa tra Medioevo ed età moderna, Roma, 2003; o S. MOSHER STUARD, Gilding the Market: Luxury and Fashion in Fourteenth Century Italy, Filadelfia, 2005.

44 J. SEMPERE y GUARINOS, Historia del lujo y de las leyes suntuarias de España, Madrid, 1788, reeditada por J. RICO GIMÉNEZ en Valencia, 2000. Destaca para la Corona de Castilla J.D. GONZÁLEZ ARCE, Apariencia y poder. La legislación suntuaria castellana en los siglos XIII-XV, Jaén, 1998. De la Corona de Aragón véase por ejemplo R. CONDE y DELGADO DE MOLINA, "Vestit i societat: les ordinacions 
Se puede decir de estas normativas que trataron de ser un freno para los cambios sociales, pero sería simplificar en exceso su contenido. En realidad no todas eran iguales: unas eran promulgadas por los municipios, y otras por la Corona, a través de las Cortes, unas trataban de premiar el esfuerzo bélico y otras solo de contener los gastos para detener la ruina de los más ricos, ocasionada por los derroches consumistas; algunas afectaban a toda la población, sin distinciones en función de los estamentos, y otras trataban de "demostrar la diferencia entre las personas", como aparece a veces en sus retóricos preámbulos ${ }^{45}$.

En general, sin embargo, se puede aceptar que en el caso hispánico las leyes suntuarias más antiguas parecen proceder más de los monarcas que de los municipios. Así ocurre en el s. XIII, donde tanto en las Partidas castellanas como en los Furs de Valencia se recogen ordenanzas que relacionan la capacidad de gastar, especialmente en indumentaria, con la contribución que cada uno hacía a la guerra y la defensa del territorio ${ }^{46}$. Algo bastante lógico en el ambiente de frontera con el Islam propio de estas tierras, y que se prolonga hasta bien entrado el s. XIV, como ocurre por ejemplo con un fuero valenciano de 1358, no por casualidad aprobado en plena guerra con Castilla, por el que Pedro el Ceremonioso favorece que "por las diferencias en las vestiduras y los arneses sean conocidos los hombres de honor y sus mujeres", considerando como tales a los que mantenían un caballo y armas con las que contribuir a la defensa del reino ${ }^{47}$. Esos recursos bélicos, en una época en que los ejércitos se componían aún en buena medida con los vasallos armados de los reyes, se premiaban con la posibilidad de llevar en la ropa, tanto el marido como su mujer, forros de ardilla o armiño, y bordados de perlas y pedrería sobre telas de seda y oro. Debemos hacer notar en todo caso que la ley se redactó en negativo, es decir, afirmando que nadie que no dispusiera de caballo y armas podría lucir esas prendas, con lo que el ideal del rey obviamente era que todos pudieran vestirlas, ya que eso significaría disponer de una ingente población armada dispuesta a la defensa del reino contra los castellanos.

Pero esa primera fase pasó cuando la gran contienda "de los dos Pedros" terminó, y a partir de ahí el sentido y los objetivos de las nuevas normativas cambiaron radicalmente. En la segunda mitad del Trescientos las leyes suntuarias fueron más frecuentes en el ámbito municipal y el objetivo que declaraban era eliminar gastos superfluos y vanos. Su acumulación, en el caso valenciano, en las décadas de 1370 y 1380, debe tener una relación muy directa con el gran crecimiento económico que se vivió en la ciudad en esos años y con la expansión de la nueva moda masculina que ya hemos visto. Ante ello las ideas de austeridad de los predicadores mendicantes, como los

\footnotetext{
sumptuàries de Cervera (1344)", Misclel-lània Cerverina, 2 (1984), pp. 25-42; y P. CATEURA, Sociedad, jerarquía y poder en la Mallorca medieval, Palma, 1984.

45 Véase estos razonamientos sobre Valencia en J.V. GARCÍA MARSILLA, "Ordenando el lujo. Ideología y normativa suntuaria en las ciudades valencianas (siglos XIV y XV)", en S. BORUQUET y J.V. GARCIA MARSILLA, Mercats del luxe, mercats de l'art. La Corona d'Aragó i la Mediterrània en els segles XIV i XV, Valencia, 2015, pp. 561-591.

46 Ibid.

47 G. COLON y A. GARCÍA (eds.), Furs de València, Barcelona, 1999, vol. VIII, pp. 105-106.
} 
citados Eiximenis, Vicente Ferrer, o más tarde el castellano Hernando de Talavera ${ }^{48}$, debieron tener su importancia en la difusión de estas ordenanzas restrictivas, pero es aún más importante considerar que a través de ellas las oligarquías urbanas estaban tratando de tutelar, de forma casi podríamos decir paternalista, a los miembros de su clase, prohibiendo, al menos teóricamente, lo que consideraban despilfarros que podrían resultar peligrosos al arrastrar a la ruina y ocasionar procesos de desclasamiento de los más derrochadores.

Ya en esta época conviven las leyes locales con las generales, y ambas parecen a veces entrar en contradicción, sobre todo cuando las dictadas por los municipios pretendieron incluir también a los nobles y a la misma corte regia, que reaccionaba en ocasiones con auténtica soberbia. En 1393 por ejemplo, la reina Violant de Bar, esposa de Juan I, pidió a los dirigentes valencianos, los jurats, que levantaran las prohibiciones con motivo de su visita a Valencia, a lo que se negaron. La reina entonces amenazó con derogar a la fuerza el estatuto, y los jurats se negaron a visitarla en palacio. También María de Luna, esposa de Martín el Humano, protagonizó parecidos enfrentamientos a finales de la década de 1390, y en general, ante las ordenanzas locales los reyes inventaban subterfugios, como crear selectos clubs nobiliarios, las llamadas "empresas" u órdenes militares de naturaleza cortesana, como la de la Corretja (Correa), fundada por Martín, a la que asociaban permisos para lucir cualquier tipo de adorno, incluso los vetados por el municipio ${ }^{49}$.

Ante estos roces lo que se observa, especialmente en la segunda mitad del s. XV, son normativas más centradas en ciertas clases sociales, que excluían de forma directa o indirecta a la nobleza, y que proclamaban abiertamente que su objetivo era hacer visibles de forma inmediata las diferencias de estatus. Se ve claramente por ejemplo en las ordenanzas de Mallorca, estudiadas por Pau Cateura o Jaume Sastre. En las de 1454 por ejemplo, que reglamentaban entre otras cosas el largo de las gonelas femeninas, se establecía que las de mujeres o hijas de menestral solo podían arrastrar medio palmo, mientras que las de nobles, ciudadanos y mercaderes podían llegar a un palmo, y las de prostitutas, esclavas o libertas, no podían llegar a tierra. Más de treinta años después, en 1486, se prohibían las gonelas de seda y los briales de camelote a las mujeres de menestrales, se limitaba el número de prendas de los ciudadanos, y entre los forans o habitantes de las villas se fijaba en una contribución fiscal de 3.000 libras la diferencia entre los que podían vestirse como mercaderes (con vetas de seda, entre otras cosas) y los que debían hacerlo como artesanos ${ }^{50}$.

En general, estas eran las prohibiciones que aparecían en este tipo de normativas: no vestir ciertos tejidos más caros, no llevar bordados de hilos de oro o seda, no incorporar perlas a las vestimentas etc. En realidad debemos pensar que no sería

48 Sobre este último véase T. DE CASTRO, "El tratado sobre el vestir, calzar y comer del arzobispo Hernando de Talavera", Espacio, Tiempo y Forma. Serie III. Historia Medieval, 14 (2001), pp. 11-92.

49 Sobre estas disputas véase J.V. GARCÍA MARSILLA, "Ordenando el lujo...", op. cit. (en prensa). La creación de la empresa de la Corretja y su uso como evasiva para eludir normas suntuarias en J. RIERA I SANS, "Els heralds i les divises del rei Martí (1356-1410)", Paratge: quaderns d'estudis de geneaologia, heràldica, sigil lografia i nobiliària, 14 (2002), pp. 41-62.

50 J. SASTRE MOLL, Alguns aspectes de la vida quotidiana a la ciutat de Mallorca (època medieval), Palma de Mallorca, 1997, pp. 103-104, y P. CATEURA, op. cit., 1984, p. 202. 
numéricamente muy importante el grupo que virtualmente podía trasgredir estas normas, lo que hace que tengamos pocas pruebas sobre su efectivo cumplimiento, pero la repetición de las mismas no implica necesariamente que fueran pura palabrería o papel mojado. Los destinatarios virtuales eran gente como la llamada "na Castellana", la hija del ciudadano de Valencia Ramon Castellà, de quien decían en 1374 que estaba "tan bien provista de ropa como si fuera hija de un caballero de la ciudad", lo que desde el punto de vista taxonómico propio de la sociedad feudal llegaba a ser considerado una especie de fraude, en tanto la podían confundir con una noble ${ }^{51}$.

Conocemos, es cierto, más perdones que penas impuestas, pero aún así en las cuentas del Justicia Civil de Valencia de 1418 se registra un Compte dels fets dels arreus prohibits per fur, en el que se observan exclusivamente pagos por infracciones a estos estatutos. En el primer caso que aparece expuesto a la viuda del abogado Joan Carbonell, como "havia trameses camises de seda al sposat de sa filla", le fue embargado un plater d'argent que se vendió en subasta por 98 sueldos y 7 dineros, de los que se quedó la mitad el batle, condonando el municipio su parte. En el segundo, es el especiero Pere Comes el que debe pagar cien sueldos porque su mujer "portava bolletes en les mantons contra los furs", y de nuevo la parte correspondiente al gobierno local le fue devuelta ${ }^{52}$. Al año siguiente, 1419 , otro vecino es sancionado con motivo de una boda: es el juponer "en Roig", quien pagó por su sobrino, que era el novio, el cual "portava una camisa de seda lo dia de les noces", motivo por lo cual el jubonero satisfizo en nombre de su pariente una multa de 40 sueldos y 2 dineros $^{53}$. En todo caso, el hecho de que ese mismo año los arrendatarios del impuesto sobre los tejidos de seda y oro recibieran una compensación de dos mil sueldos por los efectos negativos que sobre el comercio de estas prendas tenían estas leyes demuestra que al menos tenían un cierto impacto entre la población ${ }^{54}$.

Sin embargo, parece que la coexistencia de dos poderes emisores de ordenanzas: los municipios y la corona con sus cortes, cuyos intereses, habitualmente concordes, podían no ajustarse siempre del todo, se acabó traduciendo en una cierta laxitud a la hora de aplicar las penas, y a veces en abiertas contradicciones entre ambos. Así, las leyes suntuarias de la Corona de Aragón nunca tuvieron una aplicación tan estricta como, por ejemplo, en algunas ciudades italianas, y desde luego la vigilancia nunca se llevó al límite, ni fue capaz de irrumpir en el ámbito más privado como ocurrió al otro lado del Mediterráneo ${ }^{55}$. Nunca, por tanto, llegaron a frenar el giro de la rueda de la fortuna, ni su aspecto más visible, el de la apariencia, que permitía el reconocimiento inmediato de unas diferencias sociales las cuales, en estos tiempos, eran cualquier cosa menos estables.

51 "ben areada de roba axí com si fos fylla de cavaller que fos en València”, ARV, Justícia Civil 4.291, Libro Judicial de Artús de Colent, 16 de mayo de 1374.

52 Ambos casos en ARV, Mestre Racional 6.493, f. $11 \mathrm{r}$.

53 ARV, Mestre Racional 6.454, f. 5 v.

54 J.V. GARCÍA MARSILLA, “Ordenando el lujo...”, op. cit. (en prensa).

55 Véanse los privilegios de irrupción en la intimidad -incluso en el interior de las casas- que aparecen en Italia en M.G. MUZZARELLI, "Una società nello specchio della legislazione suntuaria: il caso dell'EmiliaRomagna”, en M.G. MUZZARELLI y A. CAMPANINI (eds.), op. cit., 2003, pp. 17-31. 
La dinámica social, por tanto, junto con los refinamientos técnicos y la intensificación de los contactos a escala internacional, hicieron de la vestimenta un elemento comunicativo de primer orden, a cuya expresividad colaboraban las artes, pero un elemento siempre sujeto a cambios e innovaciones, y un buen termómetro de la complejidad a la que había llegado la sociedad en aquellos siglos finales de la Edad Media. La moda, invento del diablo para algunos, se convirtió entonces en un factor económico e ideológico de primer orden, y elevó lo efímero a la categoría de sublime, a mayor gloria de aquellos que eran capaces de establecer sus directrices, o al menos de seguirlas fielmente, separándose así del resto de los mortales. 